\title{
Echocardiographic evaluation of complete and incomplete Kawasaki disease in terms of coronary and non coronary cardiac involvement
}

\author{
Uttam Kumar Sarkar, Anish Chatterjee, Sumit Periwal, Suprit Basu, Indranil Dutta \\ Dr.B.C.Roy P.G.I.P.S. Kolkata, India
}

\author{
Correspondence \\ Dr. Suprit Basu \\ Dr.B.C.Roy P.G.I.P.S. Kolkata, \\ India

\section{Email:} \\ supritbasu94@gmail.com
}

DOI: http://dx.doi.org/10.3126/ jemsn.v13i1.16669

Article received: Dec $5^{\mathrm{h}} 2016$

Article accepted: J an $10^{\text {th }} 2017$

\begin{abstract}
Background \& Objectives: With increasing incidence of Kawasaki disease and its associated complications, the need of the hour is early diagnosis. Incomplete Kawasaki is often diagnosed late and is frequently associated with morbidities and mortalities. Our study aims to emphasize the importance of echocardiography in detection of incomplete Kawasaki disease. Materials \& Methods: A total of 150 children, clinically diagnosed as Kawasaki disease were evaluated echocardiographically and involvement of coronary artery and associated cardiac involvements were studied. Results: Amongst the incomplete Kawasaki disease patients $76 \%$ were from extremes of ages and $19.2 \%$ of them had coronary involvement. Myocarditis(38.1\%) was the commonest noncoronary findings. Conclusion: Atypical Kawasaki disease is more common in extremes of ages and echocardiography helps in detecting atypical disease at the earliest, thus facilitating prompt treatment and reducing complications.
\end{abstract}

Key words: Incomplete kawasaki disease; myocarditis; non-coronary cardiac involvement

Citation: Sarkar UK, Chaterjee A, Periwal S, Basu S, Dutta I. Echocardiographic evaluation of complete and incomplete Kawasaki disease in terms of coronary and non coronary cardiac involvement. JCMS Nepal. 2017;13(1):220-4.

\section{INTRODUCTION}

Kawasaki disease is a silent endemic of the present century. Kawasaki disease was first described in 1967, by a Japanese paediatrician, Tomisako Kawasaki. ${ }^{1}$ He characterised the illness and termed it as muco-cutaneous lymph node syndrome, presenting as high fever, non-exudative conjunctivitis, inflammation of the oral mucosa, rash, cervical lymphadenopathy, and findings in the limbs, including swollen hands and feet, red palms and soles, and later subungual peeling. At that time, the disease was thought to be self-limited, without long term consequences. Later, Kawasaki disease was shown to cause coronary arterial aneurysms, which may cause complications like angina, myocardial infarction and sudden death. ${ }^{2}$

The male-to-female ratio is 1.5 to 1 . It occurs primarily in young children, with a peak incidence between one to two years of age, $80 \%$ of patients are younger than four years of age and $50 \%$ are younger than two years of age. ${ }^{3}$ It is now the most common pediatric vasculitis, the most common cause of myocardial infarction for children and the most common cause for acquired heart disease in children in Japan, North America and Europe. It is being increasingly reported from developing countries like India. ${ }^{4}$

The cause is unknown. Different infectious causes on the basis of a genetic or immunological predisposition are suspected. Being a vasculitic disorder involving small and medium sized arteries along with heart it involves other organs also. Coronary involvement starts with necrotising neutrophilic arteritis. This is followed by a sub-acute inflammatory vasculitis and stenosing proliferative myofibroblastic lesions. ${ }^{4}$ Hence along with coronary involvement a myriad of soft cardiological signs including myocarditis, valvular regurgitation, aortic root dilation, pericardial effusion etc. are also seen 
in Kawasaki Disease.

\section{MATERIALS AND METHODS}

Study design- cross-sectional study to look for echocardiographic abnormality in complete and incomplete Kawasaki disease.

Study site - Dr.B.C.Roy Post Graduate Institute of Pediatric Sciences Kolkata, a tertiary care pediatric hospital in Kolkata.

Study population- patients presenting with features suggestive of complete or incomplete Kawasaki disease.

Inclusion criteria-

Classical Diagnostic Clinical Criteria of Kawasaki Disease prepared by the American Heart Association:

A. Fever $>=$ five days

B. Presence of any four or more of the following-

- Changes in extremities

- Polymorphous exanthema

- Bilateral bulbar conjunctival injection without exudates

- Changes in lip and extremities

- Cervical lymphadenopathy $(>1.5 \mathrm{~cm})$

C. Exclusion of other diseases with similar findings Incomplete or atypical Kawasaki disease refers to patients who do not fulfil the classic criteria of at least four of the five findings.

Exclusion criteria- congenital heart disease patients

Study tools- echocardiographic assessment was done in our cardiology department

Data analysis- data were entered in Microsoft excel spread sheet and were analyzed.

\section{RESULTS}

Out of 150 Kawasaki disease patients, 129 were complete Kawasaki disease and 21 had incomplete presentations. Of them $54 \%$ (81 of 150 ) children were between one to five years of age ,23\% (35 of $150)$ were between five to eight years of age and $22 \%$ children were from extremes of ages. Of them $15 \%$ (22 of 150$)$ were infants and $7 \%$ (11 of 150 ) were more than eight years of age. . Out of 150 children $85(56 \%)$ were boys and $65(43 \%)$ were girls with male: female ratio being $1.3: 1$. In our study $14 \%$ ( 21 out of 150 ) patients presented with clinical features suggestive of incomplete Kawasaki disease. Age-wise distribution reveals 40\% (9 out of 22 infants) had incomplete features while 36\% (four out of 11) more than eight years of age had incomplete Kawasaki disease. In the 1-5 year age group and five to eight year of age, number of incomplete Kawasaki were 5\% (four of 81) and $11 \%$ (four of 35 ) respectively. In our study, 28 $(18.6 \%)$ patients had coronary involvement, of those $18(12 \%)$ of 150 patients were affected with coronary aneurysm, while $10 \quad(6.6 \%)$ had perivascular brightness of coronaries. Mitral regurgitation was found in eight patients, which consists of $5 \%$ of our subjects. In our study, we found six patients (4\%) had both aortic regurgitation and aortic root dilatation. We found that 45 out of 150 patients $(30 \%)$ had myocarditis. The significant findings were global hypokinesia (LV Systolic dysfunction) with decreased ejection fraction. We found pericardial effusion in significant number of patients; 18 out of $150(12 \%)$, though majority of them had mild effusion.

\section{DISCUSSION}

Kawasaki disease has been reported in all racial and ethnic groups, as well as across the entire paediatric age range, although in most cases $85 \%$ of the patients are younger than five years old. ${ }^{5}$ In our study $54 \%$ of children were between one to five years of age, $23 \%$ were between five to eight years of age and $22 \%$ children were from extremes of ages.

In various studies the peak incidence of $\mathrm{KD}$ was between one to two years of age. ${ }^{3}$ Patients younger than six months or older than eight years are encountered infrequently but may be at risk of having coronary artery aneurysms. ${ }^{5,6}$ The lowincidence in the first six months suggests that most infants are protected by acquired maternal antibodies. $^{7}$

Senzaki $\mathrm{H}$ et $\mathrm{al}^{10}$ found male patients outnumber female patients (male/female ratio: 1.2 to 1.7 ). We also found the similar trend girls with male: female ratio being 1.3:1.

Incomplete or atypical Kawasaki disease refers to patients who do not fulfil the classic criteria of at least four of the five findings. ${ }^{8}$ In our study $14 \%$ (21 out of 150) patients presented with clinical features suggestive of incomplete Kawasaki disease which is comparable with study by $\mathrm{Yu} \mathrm{JJ}$ et $\mathrm{al}^{9}$ where prevalence of incomplete presentation was $15 \%$ to $36.2 \%$ among patients with Kawasaki disease and relatively more children with incomplete presentation reported were in the extremes of the age spectrum ( $\leq 1$ year old, or $\geq 5$ to nine years old). In our study also $76 \%$ of atypical Kawasaki were of extremes of ages. It is also broadly agreed that KD can be diagnosed in the absence of full criteria when coronary abnormalities 
Table 2 Distribution of echocardiographic findings

\begin{tabular}{|c|c|c|c|c|}
\hline \multirow[t]{2}{*}{$\begin{array}{l}\text { Echocardiographic } \\
\text { findings }\end{array}$} & \multicolumn{2}{|c|}{ Complete Kawasaki disease $(n=129)$} & \multicolumn{2}{|c|}{$\begin{array}{l}\text { Incomplete Kawasaki disease } \\
(n=21)\end{array}$} \\
\hline & $\begin{array}{l}\text { Coronary findings } \\
\text { (24patients) }\end{array}$ & $\begin{array}{l}\text { Non- } \\
\text { coronary } \\
\text { findings }\end{array}$ & $\begin{array}{l}\text { Coronary } \\
\text { findings ( } 4 \\
\text { patients) }\end{array}$ & $\begin{array}{l}\text { Non- coronary } \\
\text { findings }\end{array}$ \\
\hline Coronary aneurysm & $15(11.6 \%)$ & - & $3(14.4 \%)$ & - \\
\hline Perivascular brightness & $9(6.9 \%)$ & - & $1(4.8 \%)$ & - \\
\hline Pericardial effusion & - & $13(10 \%)$ & - & $5(23.8 \%)$ \\
\hline Myocarditis & - & $37(28.7 \%)$ & - & $8(38.1 \%)$ \\
\hline Mitral regurgitation & - & $6(4.6 \%)$ & - & $2(9.5 \%)$ \\
\hline Aortic regurgitation & - & $4(3.1 \%)$ & - & $2(9.5 \%)$ \\
\hline Aortic root dilatation & - & $4(3.1 \%)$ & - & $2(9.5 \%)$ \\
\hline
\end{tabular}

are present. ${ }^{9}$

Cardiac involvement is the most important manifestation of Kawasaki disease (KD). Up to $25 \%$ of untreated children will develop permanent damage to the coronary arteries in the second to third wk of illness. ${ }^{11}$ Giant coronary artery aneurysms (classic definition of $>8 \mathrm{~mm}$ internal diameter) pose the greatest risk for rupture, thrombosis or stenosis, and myocardial infarction. ${ }^{11}$

Previous studies have shown varying degrees of coronary involvement in Kawasaki disease ranging from $7-25 \%$ of untreated cases. ${ }^{5,12}$ In our study, we found $18(12 \%)$ patients were affected with coronary aneurysm, while $10(6.6 \%)$ patients had perivascular brightness of coronary arteries. There was no giant aneurysm in our study.

Although coronary artery sequelae are responsible for the major morbidity and mortality of $\mathrm{KD}$, acute $\mathrm{KD}$ is often accompanied by noncoronary cardiac abnormalities, including left ventricular (LV) dysfunction, valvular regurgitation, pericardial effusion, and aortic root dilation. ${ }^{13,14}$ During acute $\mathrm{KD}$, approximately $2 \%$ of patients will develop valvulitis, followed by scarring of the valve leaflets. $^{15}$ Mitral insufficiency is a serious complication of Kawasaki disease. During the acute phase of Kawasaki disease, mitral insufficiency may be secondary to active valvulitis, papillary muscle dysfunction or myocardial infarction16. In rare cases acute mitral regurgitation can be severe. ${ }^{17}$ Mitral regurgitation was found in eight $(5 \%)$ patients in our study. Kato et $\mathrm{al}^{18}$ reported six patients $(1.0 \%$ of their series $)$ with mitral regurgitation in the acute or subacute stage of Kawasaki disease, with resolution in three patients, death from MI in two, and persistence from papillary muscle dysfunction in one. According to a study by Printz et al. ${ }^{19}$ at least mild MR was noted in $27 \%$ of subjects on their baseline Echocardiogram and their findings was similar to the $23 \%$ reported cases of MR by Giddings et al. ${ }^{20}$ but lower than the $47 \%$ reported by Suzuki et al. ${ }^{21}$ These differences might be because different treatment eras were examined or because qualitative rather than quantitative definitions of MR were employed. ${ }^{19}$ These lesions mostly disappear with the resolution of acute illness, ${ }^{21}$ but a very small group of the lesions persist and progress. ${ }^{22}$

Aortic regurgitation has been documented angiographically by Nakano et $\mathrm{al}^{23}$ in $5 \%$ of children with Kawasaki disease and was attributed to valvulitis. Other investigators have observed a much lower incidence of aortic regurgitation in the acute phase ${ }^{24}$ but late-onset aortic regurgitation has been reported as an exceedingly rare finding after Kawasaki disease and may be associated with the need for aortic valve replacement. ${ }^{25}$ Aortic root dilation has also been noted in Kawasaki disease. ${ }^{26}$ In our study, we found six patients (4\%) had both aortic regurgitation and aortic root dilatation. According to a study by Printz et al. ${ }^{19}$ aortic root dilation was present in $8 \%$ of their patients.

Focus on the coronary aneurysms has diverted attention from other potential cardiovascular complications of KD like myocarditis. Diffuse 
myocarditis followed by myocardial fibrosis may lead to systolic or diastolic dysfunction in a subset of KD patients. ${ }^{27,28}$ Histologic evidence of myocarditis in the acute phase of Kawasaki disease is present in virtually all cases by endomyocardial biopsy $^{29}$ and in a majority of subjects when assessed by WBC-labeled radionuclide studies 30 . Myocarditis were found in $30 \%$ cases. The significant findings were global hypokinesia (LV Systolic dysfunction) with decreased ejection fraction. In various studies myocardial inflammation has been documented in $50 \%$ to $70 \%$ of patients using $67 \mathrm{Ga}$ citrate scans (planar or single photon emission CT) 31 and 99mTc-labeled white blood cell scans. ${ }^{32}$ The severity of myocarditis does not appear to be associated with the risk of coronary artery aneurysms. ${ }^{33,34}$

Identification of pericardial effusion may also be a value in assessing risk of coronary artery changes. ${ }^{20}$ In the acute phase of Kawasaki disease, pericardial inflammation can produce modest pericardial effusions. Although rarely of hemodynamic significance, there have been reports of pericardial tamponade in association with severe acute Kawasaki disease. ${ }^{35,36}$ We found pericardial effusion in significant number of patients; 18 out of $150(12 \%)$ though majority of them had mild effusion. Belay ED et al. ${ }^{37}$ in their study of Kawasaki Syndrome and Risk Factors for Coronary Artery Abnormalities in United States, 1994-2003 found pericardial effusion in $6.2 \%$ of their patients.

\section{CONCLUSION}

Early diagnosis and prompt treatment of Kawasaki disease prevents fatal coronary complications. Patient may present with complete or incomplete clinical features. Given the potential serious consequences of missing the diagnosis of Kawasaki disease in patients with incomplete manifestations of the principal clinical features, together with the efficiency and safety of early treatment with IVIG, we should be careful to establish the early diagnosis of incomplete Kawasaki disease with echocardiography to avoid missing the diagnosis of this dreaded disease. We have attempted a comprehensive study of various coronary as well as non - coronary cardiac involvements in both complete and incomplete variety of Kawasaki disease. Though echocardiography helps to diagnose Kawasaki disease even presenting with incomplete features, still clinical judgement gives the final verdict in diagnosis.

\section{REFERENCES}

1. Kawasaki T: Acute febrile mucocutaneous syndrome with lymphoid involvement with specific desquamation of the fingers and toes in children. Jpn J Allergy. 1967;116:78222 .

2. Newbueger J. Kawasaki Disease. In: Anderson RH, Baker EJ, Redington A, Rigby ML, Penny D. Wernovsky G. editors. Paediatric Cardiology. 3rd ed. Philadelphia: Elsevier; 2010. p. 1067-1078.

3. Park MK. Park's Pediatric Cardiology for Practitioners. 6th ed. Philadelphia: Elsevier; 2014. p. 342-365.

4. Agrawal S, Singh S. Medium Vessel Vasculitis: Kawasaki Disease and PolyarteritisNodosa. In: Gupta P, Menon PSN, Ramji S, Lodha R. editors. PG Textbook of Paediatrics. New Delhi: Jaypee Brothers;2015. p. 2539-2542.

5. Kim DS. Kawasaki disease. Yonsei Med J. 2006 Dec 31;47 (6):759-72. DOI: 10.3349/ymj.2006.47.6.759. PMID: 17191303.

6. Saguil A, Fargo M, Grogan S. Diagnosis and management of Kawasaki disease. Am Fam Physician. 2015;91:365-371. PMID: 25822554.

7. Binder E, Griesmaier E, Giner T, Sailer-Höck M, Brunner J.Kawasaki disease in children and adolescents: clinical data of Kawasaki patients in a western region (Tyrol) of Austria from 2003-2012. Pediatric Rheumatology. 2014;12:37

8. Yu JJ. Diagnosis of incomplete Kawasaki disease.Korean J Pediatr. 2012 Mar;55(3):83-7.

9. Newburger JW, Takahashi M, Gerber MA, Gewitz MH, Tani LY, Burns JC, et al. Diagnosis, treatment, and longterm management of Kawasaki disease: a statement for health professionals from the Committee on Rheumatic Fever, Endocarditis and Kawasaki Disease, Council on Cardiovascular Disease in the Young, American Heart Association. Circulation. 2004 Oct 26;110(17):2747-71. DOI: 10.1161/01.CIR.0000145143.19711.78. PMID: 15505111.

10. Senzaki H. Long-term outcome of Kawasaki disease. Circulation. 2008;118:2763-2772. DOI: 10.1161/ CIRCULATIONAHA.107.749515. PMID: 19106401.

11. Son MB, Newburger JW. Kawasaki Disease. In: Kliegman RM, Stanton BF, St Geme JW, Schor NF, editors. Nelson Textbook of Pediatrics. 20th ed. Philadelphia: Elsevier; 2016. p. 1209-1214. DOI: $10.1016 / \mathrm{b} 978-0-323-24145-$ 8.00035-1.

12. Chiang CY, Ho CH, Chu CC, Chen ZC, Wang JJ, Tseng YZ. Coronary Artery Complications in Pediatric Patients with Kawasaki Disease: A 12-Year National Survey. Acta Cardiol Sin. 2013 Jul;29(4):357-65. DOI: PMID: 27122730.

13. Newburger JW, Sanders SP, Burns JC, Parness IA, Beiser AS, Colan SD. Left ventricular contractility and function in Kawasaki syndrome. Effect of intravenous gammaglobulin. Circulation. 1989;79:1237-46. DOI: 10.1161/01.CIR.79.6.1237. PMID: 2720925.

14. Moran AM, Newburger JW, Sanders SP, Parness IA, Spevak PJ, Burns JC et al. Abnormal myocardial mechanics in Kawasaki disease: rapid response to gammaglobulin. Am Heart J. 2000 Feb;139(2 Pt 1):217-23. DOI: 10.1067/mhj.2000.101221.

15. Nakamura Y, Yashiro M, Uehara R, Oki I, Watanabe M, Yanagawa H. Epidemiologic features of Kawasaki disease in Japan: results from the nationwide survey in 2005-2006. J Epidemiol 2008;18:167-72. DOI: 10.2188/ jea.JE2008001. PMID: 18635901.

16. Kitamura S, Kawashima Y, Kawachi K, Harima R, Ihara $\mathrm{K}$, Nakano $\mathrm{S}$ et al. Severe mitral regurgitation due to coronary artentis of mucocutaneous lymph node syndrome. A new surgical entity. J Thorac Cardiovasc Surg. 1980 Oct;80(4):629-36. PMID:7421297.

17. Tomita H, Sawada Y, Higashidate Y, Chiba S, Ito S, Kogasaka R. Mitral regurgitation with gross deformity of a mitral leaflet due to Kawasaki disease. Pediatr Cardiol. 
1990 Jul;11(3):153-5. DOI: 10.1007/BF02238847. PMID: 2395744.

18. Kato H, Sugimura T, Akagi T, Sato N, Hashino K, Maeno $\mathrm{Y}$ et al. Long-term consequences of Kawasaki disease. A 10- to 21-year follow-up study of 594 patients. Circulation. 1996;94:1379-1385. DOI: 10.1161/01.CIR.94.6.1379. PMID: 8822996

19. Printz BF, Sleeper LA, Newburger JW, Minich LL, Bradley T, Cohen MS et al. Noncoronary cardiac abnormalities are associated with coronary artery dilation and with laboratory inflammatory markers in acute Kawasaki disease. J Am Coll Cardiol. 2011 Jan 4;57(1):8692. DOI: 10.1016/j.jacc.2010.08.619. PMID:21185506.

20. Giddings SS, Duffy CE, Pajcic S, Berdusis K, Shulman ST. Usefulness of echocardiographic evidence of pericardial effusion and mitral regurgitation during the acute stage in predicting development of coronary arterial aneurysms in the late stage of Kawasaki disease. Am J Cardiol. 1987;60:76-9. DOI: 10.1016/0002-9149(87)90988-X.

21. Suzuki A, Kamiya T, Tsuchiya K, Sato I, Arakaki Y, Kohata $\mathrm{T}$ et al. Tricuspid and mitral regurgitation detected by color flow Doppler in the acute phase of Kawasaki Disease. Am J Cardiol. 1988 Feb 1;61(4):386-90. DOI: 10.1016/0002-9149(88)90950-2.

22. Akagi T, Kato H, Inoue O, Sato N, Imamura K. Valvular heart disease in Kawasaki syndrome: incidence and natural history. Am Heart J. 1990 Aug;120(2):366-72. DOI: 10.1016/0002-8703(90)90081-8.

23. Nakano H, Nojima K, Saito A, Ueda K. High incidence of aortic regurgitation following Kawasaki disease. J Pediatr. 1985;107:59-63. DOI: 10.1016/S0022-3476(85)80615-6.

24. Gordon JB, Kahn AM, Burns JC. When children with Kawasaki Disease grow up: myocardial and vascular complications in adulthood. J Am CollCardiol 2009;54:1911-20. DOI: $\quad 10.1016 /$ j.jacc.2009.04.102. PMID: 1990987.

25. Gidding SS. Late onset valvular dysfunction in Kawasaki disease. ProgClinBiol Res. 1987;250:305-309. PMID: 3423044.

26. Ravekes WJ, Colan SD, Gauvreau K, Baker AL, Sundel $\mathrm{RP}$, van der Velde $\mathrm{ME}$ et al. Aortic root dilation in Kawasaki disease. Am J Cardiol. 2001;87:919-922. DOI: 10.1016/S0002-9149(00)01541-1.

27. Nagasawa H, Arakaki Y, Yamada O, Nakajima T, Kamiya T. Longitudinal observations of left ventricular enddiastolic dimension in children using echocardiography. PediatrCardiol 1996;17:169 -74. DOI: 10.1007/ bf02505207.

28. Kurotobi S, Kawakami N, Shimizu K, Aoki H, Nasuno S, Takahashi $\mathrm{K}$ et al. Brain natriuretic peptide as a hormonal marker of ventricular diastolic dysfunction in children with Kawasaki disease. Pediatr Cardiol. 2005 Jul-Aug;26(4):425 -30. DOI: 10.1007/s00246-004-0812-4. PMID: 15633045.

29. Yutani C, Go S, Kamiya T, Hirose O, Misawa H, Maeda H et al. Cardiac biopsy of Kawasaki Disease. Arch Pathol Lab Med. 1981 Sep;105(9):470-3. PMID: 6895017.

30. Kao CK, Hsieh KS, Chen YC, Wang YL, Wang SJ. Relationships between coronary artery dilatation and severity of carditis detected by two-dimensional echocardiography and [99mTc] HMPAO-labeled white blood cell heart scan in children with Kawasaki disease. PediatrRadiol. 1994;24:41-4. DOI: 10.1007/bf02017659.

31. Matsuura H, Ishikita T, Yamamoto S, Umezawa T, Ito R, Hashiguchi R, et al. Gallium-67 myocardial imaging for the detection of myocarditis in the acute phase of Kawasaki disease (mucocutaneous lymph node syndrome): the usefulness of single photon emission computed tomography. Br Heart J. 1987;58:385-392. DOI: 10.1136/ hrt.58.4.385. PMID: 3499926

32. Klassen TP, Rowe PC, Gafni A. Economic evaluation of intravenous immune globulin therapy for Kawasaki syndrome. J Pediatr. 1993;122:538-542. DOI: 10.1016/ S0022-3476(05)83532-2.
33. Anderson TM, Meyer RA, Kaplan S. Long-term echocardiographic evaluationof cardiac size and function in patients with Kawasaki disease. Am Heart J. 1985;110:107 -115. DOI: 10.1016/0002-8703(85)90523-X.

34. Hiraishi S, Yashiro K, Oguchi K, Kusano S, Ishii K, Nakazawa K. Clinical course of cardiovascular involvement in the mucocutaneous lymph node syndrome. Relation between clinical signs of carditis and development of coronary arterial aneurysm. Am J Cardiol. 1981;47:323330. DOI: 10.1016/0002-9149(81)90404-5.

35. Dahlem PG, von Rosenstiel IA, Lam J, Kuijpers TW. Pulse methylprednisolone therapy for impending cardiac tamponade in immunoglobulin-resistant Kawasaki disease. Intensive Care Med. 1999;25:1137-1139. DOI: 10.1007/ s001340051025. PMID: 10551972.

36. Ozdogu H, Boga C. Fatal cardiac tamponade in a patient with Kawasaki disease. Heart Lung. 2005;34:257-259. DOI: 10.1016/j.hrtlng.2004.12.003. PMID:16027646.

37. Belay ED, Maddox RA, Holman RC, Curns AT, Ballah K, Schonberger LB. Kawasaki syndrome and risk factors for coronary artery abnormalities: United States, 1994-2003. Pediatr Infect Dis J. 2006;25:245-249. DOI: 10.1097/01.inf.0000202068.30956.16. PM: 16511388 . 